\title{
Analysis of the Kadoma General Hospital Cervical Cancer Screening Program Dataset, 2014-2015
}

\author{
Article by Pamela N. Magande \\ Bachelors in Medicine and Surgery, University of Zimbabwe, Zimbabwe \\ Email:pmagande@gmail.com
}

\begin{abstract}
Analysis of the Kadoma General Hospital Cervical Cancer Screening Program Dataset, 2014-2015

Pamela N. Magande, Daniel Chirundu, Notion Gombe, More Mungati, Donewell Bangure, Mufuta Tshimanga

Introduction: Early diagnosis of cervical cancer results in successful treatment. Visual Inspection with acetic Acid and Cervicography (VIAC) is an effective method of cervical cancer screening being used in Zimbabwe. In Kadoma screening started in 2014, 2506 clients had been screened in July 2015. Factors associated with VIAC positivity were determined since VIAC positivity was low, $3 \%$.

Materials and methods: An analytical cross sectional study based on secondary dataset analysis was conducted in 2015. All the 2506 clients were included. The data was exported from an electronic database into Epi Info 7TM (CDC. 2014). Frequencies and means were generated using this software. Bivariate analysis and multilogistic regression were also performed.
\end{abstract}

Results: Among the clients who were screened, $81 \%$ were married. The median age was 39.7 years $(Q 1=31 ; Q 3=47)$. The median number of children was two $(Q 1=2 ; Q 3=4)$. Early sexual debut, $<16$ years (POR $=2.37(1.47-3.83), \quad p$ value $<0.05)$, being single $(P O R=1.92(1.21-3.12), p$ value $=0.005)$, being HIV positive $(P O R=3.87(2.40-6.23), p<0.05)$, history of STI (POR=1.83(1.05-3.15), $p=0.03),(P O R=2.79(1.17-6.65), p$ value $=0.015)$ were significant risk factors. The significant protective factor was having one sexual partner (POR=0.45(0.29-0.70), $p$ value $<0.05)$. The independent risk factor was being HIV positive $(a O R=4.16(2.56-6.77), p$ value $<0.05)$. The independent protective factors were delaying sexual debut, $a O R=0.53$ (0.32-0.87), $p$ value $=0.012$ and regular condom use $a O R=0.28$ (0.086-0.92), $p$ value $=0.036$.

Conclusion: VIAC should be routine care for the HIV positive. Efforts should be intensified to promote delaying sexual debut and prevent STIs.

Key words: VIAC, Cervical Cancer, Kadoma Zimbabwe

\section{Introduction}

Zimbabwe adopted Visual Inspection with Acetic Acid and Cervicography (VIAC) as a method of screening for cervical cancer in 2013. The aim is to cost-effectively identify and treat early lesions of cervical cancer. Subsequently, Kadoma General Hospital started screening clients using VIAC in 2014. Preliminary analysis of the Kadoma VIAC data revealed that the prevalence of pre-cancer lesions of the cervix in Kadoma was low, 3\%. We therefore, analysed the data in order to assess the factors associated with pre- cancerous lesions among clients seeking the service at Kadoma General and advise on how to focus the screening program.

\section{Methodology}

\section{Study Design}

An analytical cross sectional study based on secondary dataset analysis was conducted. 
South American Journal of Public Health

Special Edition May 2016

\section{Study Population}

All clients who sought care at Kadoma General Hospital VIAC unit, from January 2014 to July 2015 were the study population.

\section{Study Unit}

An individual client record in the VIAC register at Kadoma General Hospital was the study unit.

\section{Sample Size}

All the 2506 client records in the dataset were analysed.

\section{Study setting}

The study setting was Kadoma General Hospital, Mashonaland West Province Zimbabwe.

\section{Data capturing and analysis}

The primary data source was the VIAC register at Kadoma General Hospital. All the records are in an electronic database. The VIAC Excel database was imported into Epi Info 7TM (CDC, 2014). Variables were recorded and analysed. The software was used to calculate frequencies, means and odds ratios. Bivariate analysis was used to investigate the association between dependent and independent variables. Logistic regression was used to identify independent factors.

\section{Definition of Variables}

The outcome (dependent) variable was the VIAC result (whether positive or negative). All aceto-white lesions whether just VIAC positive or suspicious of cancer were classified as 'VIAC positive' for this study. The independent variables included: age, marital status, parity, age at sexual debut, condom use, ever treated for STI, type of STI, HIV status, number of lifetime sexual partners, prior cervical cancer screening.

\section{Ethical Considerations}

Permission to carry out the study was sought from the Provincial Medical Director for Mashonaland West Province, the Kadoma General Hospital Medical Superintendent, Kadoma District Medical Officer and from the Health Studies Office. Confidentiality was maintained by not including the names of the clients during analysis and report writing.

\section{Results}

\section{Description of Data Set}

The total number of entries in the dataset was 2,506. The number of variables of interest were $^{12}$. Ten of the variables were completed for all clients. The completeness of the variables "age at sexual debut" and "HIV test results" were $99 \%$. This is presented in Table 1

\section{Demographic Characteristics}

Among the clients who were screened, $81 \%$ were married. The median age was 39.7 years $(\mathrm{Q} 1=31 ; \mathrm{Q} 3=47)$. The median number of children was two $(\mathrm{Q} 1=2 ; \mathrm{Q} 3=4)$. The number of children ranged from zero to 12 . The median age at sexual debut was 19 years $(\mathrm{Q} 1=18$ : Q3 $=21)$. The median number of lifetime sexual partners was two $(\mathrm{Q} 1=1 ; \mathrm{Q} 3=2)$. Some of the demographic characteristics of the clients are summarised and presented in Table 2. Among the clients who presented for VIAC screening 97\% were self-referrals.

\section{VIAC Results}

Amongst the 2,506 clients who were screened, 85(3\%) were VIAC positive. VIAC positivity rate by age group is presented in Figure 1. VIAC positivity increased with age from the $<21$ years peaking in the 31 to 40 years age group followed by a decline thereafter. 
Another peak is in the over 50 year age group. There was no significant difference between the proportions within age groups. (Chi square $=0.73, \mathrm{p}=0.39$ )

\section{Factors Associated with VIAC Positivity}

The socio-demographic factors associated with VIAC positivity are presented in Table 3. Those who had early sexual debut, $<16$ years were more likely to have pre-cancerous lesions compared to those who had late sexual debut, $>16$ years. This was statistically significant. $(\mathrm{POR}=2.37(1.47-3.83), \mathrm{p}$ value $<0.05)$. Being single was a significant risk factor for having pre-cancerous lesions of the cervix $(\mathrm{POR}=1.92(1.21-3.12)$, $\mathrm{p}$ value $=0.005)$. Those who had prior cervical cancer screening were more likely to have pre-cancerous lesions of the cervix $(\mathrm{POR}=3.85(1.30-11.1), \mathrm{p}$ value $=0.03)$.

The significant protective factor was having one sexual partner $(\mathrm{POR}=0.45(0.29-0.70), \mathrm{p}$ value $<0.05)$. Having less than four children $(\mathrm{POR}=0.79(0.47-1.33)$, $\mathrm{p}$ value $=0.38)$, using hormonal contraception, $(\mathrm{POR}=0.81(0.50-1.30), \mathrm{p}$ value $=0.38)$ and regular condom use $(\mathrm{POR}=0.53(0.17-1.71), \mathrm{p}$ value $=0.28)$ were also protective. This was however not statistically significant.

Fifty-seven percent of the clients were HIV negative, $18 \%$ were HIV positive and $25 \%$ had an unknown HIV status.

Being HIV positive was a significant risk factor for having pre-cancerous cervical lesions $(\mathrm{POR}=3.87(2.40-6.23), \mathrm{p}<0.05)$. Those who had a history of STI were more likely to have pre-cancerous lesions of the cervix and this was statistically significant ( $\mathrm{POR}=1.83(1.05-$ 3.15), $\mathrm{p}=0.03$ ). After stratifying by HIV status, HIV status was found to be a confounding variable for the association between history of STI and VIAC positivity.

The type of STI was also documented in the dataset. A history of genital ulcer disease was positively associated with pre-cancerous lesions of the cervix. This was however not statistically significant $(\mathrm{POR}=1.7(0.61-4.87), \mathrm{p}$ value $=0.29)$. Those who had a history of unspecified venereal disease were more likely to have pre-cancerous cervical lesions $(\mathrm{POR}=1.6(0.86-2.88), \mathrm{p}$ value $=0.13)$.

Amongst the documented types of STIs, genital warts had the strongest positive association with pre-cancerous lesions of the cervix. This association was statistically significant $(\mathrm{POR}=2.79(1.17-6.65)$, $\mathrm{p}$ value $=0.015)$. After stratifying by HIV status, HIV status was found to be a confounding variable for the association between genital warts and pre-cancerous lesions of the cervix.

\section{Follow up Care Given to VIAC Positive Clients at Kadoma General Hospital, 2014-2015}

Of the 2,506 clients screened $85(3 \%)$ were VIAC positive. Of these, $84(99 \%)$ had documented follow-up care. The follow-up plans are presented in Figure 2.

\section{Independent Risk Factors.}

Logistic regression was conducted. The independent risk factor for developing precancerous cervical lesions was being HIV positive $(\mathrm{aOR}=4.16(2.56-6.77)$, $\mathrm{p}$ value $<0.05)$. The independent protective factors were delaying sexual debut, $\mathrm{aOR}=0.53(0.32-0.87), \mathrm{p}$ value $=0.012$ and regular condom use $\mathrm{aOR}=0.28(0.086-0.92)$, $\mathrm{p}$ value $=0.036$.

\section{Discussion/Conclusion}

This analytical study based on secondary data analysis sought to determine the factors associated with VIAC positivity among clients presenting for VIAC at Kadoma General Hospital between 2014 and 2015.

The median age at sexual debut in this study was 19 years. This is similar to the results of the Zimbabwe Demographic and Health Survey 2010-2011. In that survey, the median age at sexual debut was found to be 18.5 years ${ }^{17}$. This shows that the behaviour of the clients who were screened for VIAC regarding sexual debut is comparable to the rest of the country. The 
South American Journal of Public Health

Special Edition May 2016

fact the sexual debut is at 19 years supports the Ministry of Health and Child Care's decision to give the HPV vaccine to girls age nine to 13 years.

We found a positive association between being single and a pre-cancerous lesion. Similar findings were reported by Leck et al (1978)18. This could be explained by the fact that of those who were single, $59 \%$ had more than two sexual partners. Amongst those who were married, only $34 \%$ had more than two sexual partners. It could therefore be concluded that those who were single were exposing themselves to HPV which causes cervical cancer ${ }^{6}$.

Early sexual debut, $<16$ years was a significant risk factor for pre-cancerous cervical lesions. This is consistent with the findings from an analytical cross sectional study by Makuza et. al. (2013) who reported that early sexual debut was a risk factor for pre-cancerous cervical lesions ${ }^{19}$. Murthy et. al. (2000) and Biswas et.al(1997)also reported consistent findings ${ }^{20,21}$. This is biological plausible in that early sexual debut exposes the still developing cervix to HPV and thereby making the women vulnerable to infection. In light of these findings it is important to give health education and inform girls to delay sexual debut to prevent cervical cancer.

Having a history of STI is positively associated with pre-cancerous cervical lesions. This is biologically plausible since HPV which causes cervical cancer is sexually transmitted ${ }^{22}$. This is consistent with results from studies by Gedefaw et, al(2013) and Brown et. al.(2015) who found that history of sexually transmitted disease was associated with precancerous lesions of the cervix ${ }^{12,13}$. HIV in this study is a confounding variable for the association between history of STI and VIAC positivity. The independent risk factor for pre-cancerous cervical lesions in this study was being HIV positive. The association of pre-cancerous cervical lesions and HIV is well documented in literature ${ }^{23,24.25}$. A history of genital warts has the strongest association with pre-cancerous lesions of the cervix. The HPV virus which causes genital warts also causes cervical cancer. According to Wiley et al.(2002) genital warts are the most common recognized clinical manifestation of genital HPV infection ${ }^{26}$. This finding underscores the need to intensify on-going efforts to prevent STIs, including HIV. In Zimbabwe, regular condom use and having one faithful sexual partner is advocated for ${ }^{7}$.

In this study regular condom use was an independent protective factor. Murthy et. al. (2000) reported that the use of barrier methods of contraception like condoms help towards primary prevention of cervical cancer ${ }^{20}$. Condoms can protect against many STIs including HIV/AIDs but are not nearly as effective in preventing HPV infection. This is because the HPV also lives in the skin cells covering the pubic area and can be spread through skin contact ${ }^{7}$.

Having one sexual partner was negatively associated with pre-cancerous cervical lesions. The results are consistent with findings by Gedefaw et.al (2013) and Makuza et. al.(2013) who reported that having more than one sexual partner was a risk factor for pre-cancerous cervical lesions $^{12,19}$.

Having fewer children $(<4)$ was negatively associated with pre-cancerous lesions of the cervix. This contradicts with findings by Makuza et. al.(2013) who reported that higher number of children born $(\mathrm{OR}=0.42 ; 95 \% \mathrm{CI}=(0.23,0.76))$ was negatively associated with pre-cancerous lesions of the cervix ${ }^{19}$. This difference is an area that requires further study since there are few documented studies in the Zimbabwean setting.

The association between use of hormonal contraception and pre-cancerous cervical lesions is controversial. In this study, the use of hormonal contraception was not significantly negatively associated with pre-cancerous cervical lesions ( $p$ value $=0.38$ ). This is not biologically plausible and has not been documented in literature. This not consistent with the findings of Huchko et. al.( 2014) who reported that use of a progesterone implant was associated with increased detection of precancerous ${ }^{27}$. Coker et.al (1992) and Bertram (2004) who reported that there is no positive association between precancerous lesions of the cervix and the use of hormonal oral contraceptives ${ }^{28,29}$. There is need for further studies in this area.

It should be routine care for all HIV positive women to have cervical cancer screening since they are at a significantly higher risk of developing pre-cancerous lesions of the cervix. 
HIV positive women should be encouraged to seek care at cervical cancer screening units. Girls should be encouraged from an early age to delay sexual debut and reduce the risk of precancerous cervical lesions. This would then complement the Human Pappiloma Virus vaccination that is still being piloted in the country.

\section{Acknowledgements}

We would like to acknowledge all those who helped to make this study possible. Special mention goes to the MPH FETP program and the Centres for Disease Control and Prevention. To the VIAC team at Kadoma General Hospital, we are especially grateful for their patience.

\section{References}

[1.] Ajah LO, Chigbu CO, Ozumba BC, Oguanuo TC, Ezeonu PO,(2015) Is there any association between hormonal contraceptives and cervical neoplasia in a poor Nigerian setting?, Dove Press Journal, , OncoTargets and Therapy, 8, 1887-1892.

[2.] Basu PS, Sankaranarayanan R, Mandal R, Roy C, Das P, Choudhury D,et.al.; (2003)Visual inspection with acetic acid and cytology in the early detection of cervical neoplasia in Kolkata, India. Calcutta Cervical Cancer Early Detection Group, International Journal of Gynecological Cancer, 13(5): 626-32.

[3.] Brown B, Bristow C, Iñiguez R.I, Magis-Rodriguez C, Silverman J.G, Meckel-Parker K, et. al, (2015)Prevalence And Risk Factors Of Cervical Abnormalities Among Female Sex Workers In Mexico, International Papillomavirus Conference. Lisbon, Portugal, .

[4.] Biswas LN, Manna B, Maiti PK, Sengupta S, (1997)Sexual risk factors for cervical cancer among rural Indian women: a case-control study, Int J Epidemiol. 26(3):491-5.

[5.] Betram CC, (2004) Evidence for practice: oral contraception and risk of cervical cancer, $J$ Am Acad Nurse Pract. 16(10):455-61.

[6.] Coker A, McCann MS, Hulka BS,Walton LA, (1992) Oral contraceptive use and cervical intraepithelial neoplasia , J Clin Epidemiol;45(10):1111-8.

[7.] Chokunonga E, Borok M.Z, Chirenje Z.M, Nyakabau A.M, Zimbabwe Cancer Registry, 2010, 14

[8.] Franceschi S, Dal Maso L, Arniani S, Crosignani P, Vercelli M, Simonato et al (1998),Risk factors for cancer other than Kaposi's sarcoma in persons with AIDS in Italy. Cancer and AIDS Registry Linkage Study, Br J Cancer 78:966-970

[9.] Global Cancer Facts \& Figures, : American Cancer Society; 2011, 2nd Edition, page 1,24

[10.] Gunguwo T.(2006) Zimbabwe Manual for Cervical cancer screening, Ministry of Health and Child Welfare Zimbabwe (MOHCW) and UNFPA, , 12-24

[11.] Gedefaw A, Astatkie A, Tessema GA, (2013)The Prevalence of Precancerous Cervical Cancer Lesion among HIV-Infected Women in Southern Ethiopia: A Cross-Sectional Study, PLoS ONE ,8(12) [12.] Holmes RS, Hawes SE, Touré P, Dem A, Feng Q, Weiss NS et. al, (2009),HIV Infection as a Risk Factor for Cervical Cancer and Cervical Intraepithelial Neoplasia in Senegal, Cancer Epidemiol Biomarkers Prev , 18; 2442

[13.] Huchko MJ, Leslie H,Sneden J, Maloba M, Abdulrahim N, Bukusi EA and Cohen CR, (2014), Risk factors for cervical precancer detection among previously unscreened HIV-infected women in Western Kenya, International Journal of Cancer; 134(3): 740-745

[14.] International Agency for Research against Cancer, GLOBOCAN 2012, Estimated Cancer Incidence, Mortality and Prevalence in 2012, http://globocan.iarc.fr/Pages/fact_sheets_cancer.aspx Accessed 25 August 2015

[15.] Key Informant Dr Madzima, Director Family Health Services, Ministry of Health and Child Care, Zimbabwe

[16.] Leck I, Sibary K, Wakefield J,(1978) Incidence of cervical cancer by marital status, J Epidemiol Community Health, 32(2): 108-110.

[17.] Likes W, Itano J, (2003)Human papillomavirus and cervical cancer: not just a sexually transmitted disease, Clin J Oncol Nurs, 7(3):271-6 
South American Journal of Public Health

Special Edition May 2016

[18.] Memiah P, Mbuthia W,Kiiru G, Agbor S, Odhiambo F,Ojoo S,3 and Biadgilign S,(2012) Prevalence and Risk Factors Associated with Precancerous Cervical Cancer Lesions among HIVInfected Women in Resource-Limited Settings, , AIDS Research and Treatment, 7

[19.] Makuza JD, Nsanzimana S, Muhimpundu MA, Pace LE, Ntaganira J, Riedel DJ, Prevalence and risk factors for cervical cancer and pre-cancerous lesions in Rwanda, The Pan African Medical Journal;22:26

[20.] Murthy NS, Mathew A,(2000) Risk factors for pre-cancerous lesions of the cervix. Eur J Cancer Prev. 9 (1):5-14.

[21.] Sankaranarayanan R, Wesley R, Somanathan T, Dhakad N, Shyamalakumary B, Amma NS, Parkin DM, Nair MK(1998), Visual inspection of the uterine cervix after the application of acetic acid in the detection of cervical carcinoma and its precursors, Cancer. ;83(10):2150-6.

[22.] Schiffman M, Wentzensen N, Wacholder S, Kinney W, Gage JC, Castle P. (2011)Human Papillomavirus Testing in the Prevention of Cervical Cancer, Oxford University Press, .

[23.] Sellors J, Lewis K, Kidula N, Muhombe K, Tsu V, Herdman C (2003) Screening and Management of Pre-Cancerous Lesions To Prevent Cervical Cancer in Low-Resource Settings, Asian Pacific Journal of Cancer Prevention, Volume 4, 3:277-280

[24.] Vere M, Shambira G,(2013) Risk Factors for Cervical Pre-cancer Lesions among Women Attending Cervical Cancer Screening Clinics in Harare, University of Zimbabwe, , unpublished.

[25.] World Health Organisation News, WHO supports introduction of HPV vaccine in Zimbabwe, http://www.afro.who.int/en/zimbabwe/press-materials/item/6992-who-supports-introduction-of-hpvvaccine-in-zimbabwe.html. Accessed 27 August 2015

[26.] World Health Organisation, (2006)International Agency for Research against Cancer Handbook Cancer Prevention, Volume 10 Cervix Cancer Screenings ,59-109

[27.] Wiley DJ, Douglas J, Beutner K, Cox T, Fife K, Moscicki AB,et. al. (2002), External Genital Warts: Diagnosis, Treatment, and Prevention, Clin Infect Dis, 35 (Supplement 2): S210-S224

[28.] Zondervan KT, Carpenter LM, Painter R and Vessey MP,(1996) Oral contraceptives and cervical cancer -further findings from the Oxford Family Planning Association contraceptive study, British Journal of Cancer, 73, 1291-1297

[29.] Zimbabwe National Statistics Agency (ZIMSTAT) and ICF International.( 2012) Zimbabwe Demographic and Health Survey 2010-11. Calverton, Maryland: ZIMSTAT and ICF International Inc.

\section{Tables and Figures}

Table 1: Completeness of variables in the Kadoma General Hospital dataset, 2014-2015

\begin{tabular}{ll}
\hline Variable & Completeness \\
\hline Age & $100 \%$ \\
Marital status & $100 \%$ \\
Parity & $100 \%$ \\
Age at sexual debut & $99 \%$ \\
Condom use & $100 \%$ \\
Ever treated for STI & $100 \%$ \\
Type of STI & $100 \%$ \\
HIV status & $99 \%$ \\
Number of lifetime sexual partners & $100 \%$ \\
Prior cervical cancer screening & $100 \%$ \\
\hline
\end{tabular}

Table 2: Demographic characteristics of clients presenting for VIAC at Kadoma Hospital, 2014-2015

\begin{tabular}{lrc}
\hline Variable & Frequency $n(\%)$ \\
\hline Age in years & & \\
& $16-20$ & $47(2)$ \\
& $21-30$ & $576(23)$ \\
& $31-40$ & $817(32)$ \\
& $41-50$ & $599(24)$ \\
& $51+$ & $462(19)$
\end{tabular}


Median age $=39.7(\mathrm{Q} 1=31 ; \mathrm{Q} 3=47)$

Marital Status

$\begin{array}{rc}\text { Single } & 105(4) \\ \text { Separated } & 101(4) \\ \text { Widowed } & 264(11) \\ \text { Married } & 2,033(81)\end{array}$

Parity

$$
\begin{array}{cc}
0-1 & 475(19) \\
2-4 & 1,546(62) \\
5+ & 480(19)
\end{array}
$$

Median number of children $=3 \mathrm{Q} 1=2 ; \mathrm{Q} 3=4$

Median age at sexual debut=19 Q1=18; Q3=21

Median number of lifetime sexual partners $=2$

$\mathrm{Q} 1=1 ; \mathrm{Q} 3=2$

\begin{tabular}{|c|c|c|c|c|c|}
\hline \multirow[t]{2}{*}{ Variable } & \multicolumn{2}{|c|}{ VIAC Positive } & \multirow{2}{*}{$\begin{array}{l}\text { Prevalence } \\
\text { Odds ratio }\end{array}$} & \multirow[t]{2}{*}{ CI } & \multirow[t]{2}{*}{$\mathrm{p}$ value } \\
\hline & $\operatorname{Yes}(\mathrm{n}=85)$ & $\operatorname{No}(n=2,421)$ & & & \\
\hline \multicolumn{6}{|c|}{ Age at sexual debut } \\
\hline$\leq 16$ & $25(30 \%)$ & $366(15 \%)$ & 2,37 & $1.47-3.83$ & $<0.05^{*}$ \\
\hline$>16$ & $59(70 \%)$ & $2,047(85 \%)$ & & & \\
\hline \multicolumn{6}{|c|}{ Marital Status } \\
\hline Single & $26(31 \%)$ & $447(18 \%)$ & 1.95 & $1.21-3.12$ & $0.005^{*}$ \\
\hline Married & $59(69 \%)$ & $1,974(82 \%)$ & & & \\
\hline \multicolumn{6}{|l|}{ Parity } \\
\hline$\leq 4$ & $64(77 \%)$ & $1,957(81 \%)$ & 0.79 & $0.47-1.33$ & 0.38 \\
\hline$>4$ & $19(23 \%)$ & $461(19 \%)$ & & & \\
\hline \multicolumn{6}{|c|}{ Number of lifetime sexual partners } \\
\hline $0-1$ & $35(42 \%)$ & $1,484(61 \%)$ & 0.45 & $0.29-0.69$ & $<0.05^{*}$ \\
\hline $2+$ & $49(58 \%)$ & $930(39 \%)$ & & & \\
\hline \multicolumn{6}{|c|}{ Condom use } \\
\hline Yes & $3(4 \%)$ & $156(7 \%)$ & 0.53 & $0.17-1.71$ & 0.37 \\
\hline No & $81(96 \%)$ & $2,248(93 \%)$ & & & \\
\hline \multicolumn{6}{|c|}{ Hormonal contraceptive use } \\
\hline Yes & $61(72 \%)$ & $1,837(76 \%)$ & 0.81 & $0.5-1.3$ & 0.38 \\
\hline No & $24(28 \%)$ & $584(24 \%)$ & & & \\
\hline \multicolumn{6}{|c|}{ Prior Cervical Cancer Screening } \\
\hline Yes & $4(5 \%)$ & $31(1 \%)$ & 3.85 & $1.3-11.1$ & $0.03 *$ \\
\hline No & $80(95 \%)$ & $2,388(99 \%)$ & & & \\
\hline
\end{tabular}

Table 3: Socio-demographic factors associated with of VIAC positivity at Kadoma General Hospital, 2014-2015

*Statistically significant

Table 4: Medical factors associated with of VIAC positivity at Kadoma General Hospital, 2014-2015

\begin{tabular}{rllll}
\hline Variable & \multicolumn{1}{c}{ VIAC Positive } & $\begin{array}{l}\text { Prevalence } \\
\text { Odds ratio }\end{array}$ & CI & p value \\
Yes $(\mathrm{n}=85)$ & No $(\mathrm{n}=2,421)$ & & \\
\hline HIV Positive & & & & \\
Yes 39(54\%) & $421(23 \%)$ & 3.87 & $2.40-6.23$ & $<0.05$ \\
No 33(46\%) & $1,380(77 \%)$ & & & \\
History of STI & & & $1.05-3.15$ & 0.03 \\
Yes 17(20\%) & $298(12 \%)$ & 1.83 & &
\end{tabular}


South American Journal of Public Health

Special Edition May 2016

No $\quad 66(80 \%) \quad 2,116(88 \%)$

Table 5: STIs associated with VIAC positivity at Kadoma General Hospital, 2014-2015

\begin{tabular}{|c|c|c|c|c|c|}
\hline \multirow[t]{2}{*}{ Type of STI } & \multicolumn{2}{|c|}{ VIAC Positive } & \multirow{2}{*}{$\begin{array}{l}\text { Prevalence } \\
\text { Odds ratio }\end{array}$} & \multirow[t]{2}{*}{ CI } & \multirow[t]{2}{*}{$\mathrm{p}$ value } \\
\hline & $\operatorname{Yes}(n=85)$ & $\operatorname{No}(n=2,421)$ & & & \\
\hline \multicolumn{6}{|c|}{ Genital Ulcer Disease } \\
\hline Yes & $4(5 \%)$ & $67(3 \%)$ & 1.7 & $0.61-4.87$ & 0.29 \\
\hline No & $81(95 \%)$ & $2,354(97 \%)$ & & & \\
\hline \multicolumn{6}{|c|}{ Venereal Disease (unspecified) } \\
\hline Yes & $13(15 \%)$ & $249(10 \%)$ & 1.6 & $0.86-2.88$ & 0.13 \\
\hline No & $72(85 \%)$ & $2,172(90 \%)$ & & & \\
\hline \multicolumn{6}{|l|}{ Genital warts } \\
\hline Yes & $6(7 \%)$ & $64(3 \%)$ & 2.79 & $1.17-6.65$ & 0.015 \\
\hline No & $79(97 \%)$ & $2,357(97 \%)$ & & & \\
\hline
\end{tabular}

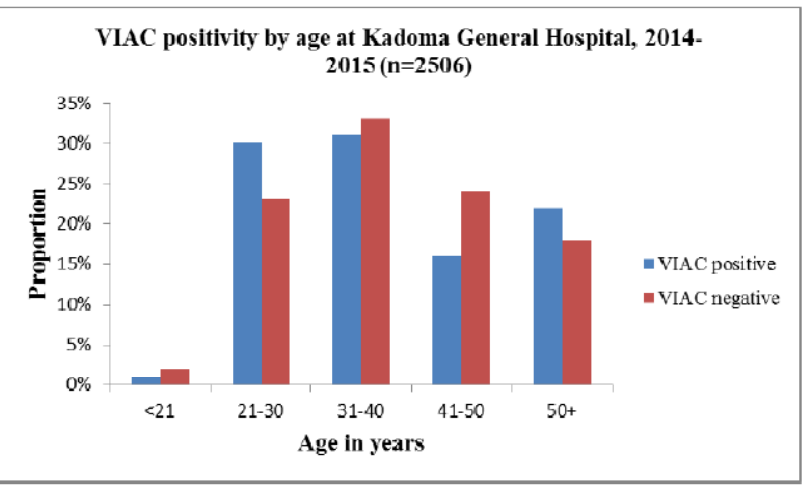

Figure 1: VIAC positivity by age-group at Kadoma General Hospital, 2014-2015

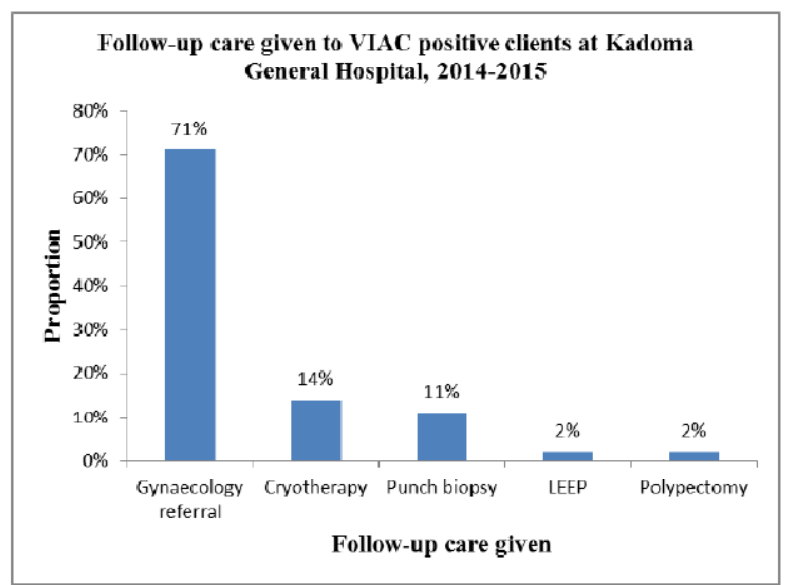

Figure 2: Follow-up care given to clients at Kadoma General Hospital, 2014-2015 